Macedonian Pharmaceutical Bulletin, 66 (Suppl 1) 189 - 190 (2020)

Online ISSN 1857 - 8969

UDC: 613.26

DOI: 10.33320/maced.pharm.bull.2020.66.03.094

Short communication

\title{
Herbal food supplements safety and future regulation challenges
}

\author{
Marjan Dzeparoski \\ Bionika Pharmaceuticals, Skupi 57, 1000 Skopje, North Macedonia
}

\section{Introduction}

A general framework for safety assessment is proposed by the EFSAs Scientific Committee, in which botanicals or botanical preparations for which an adequate body of knowledge exists could benefit from a "presumption of safety" without any need for further testing, based on long history of use without reported adverse effects and without significant larger exposition. Botanicals and botanical preparations for which a presumption of safety is not possible based on available knowledge would be subject to a more extensive safety assessment, requiring additional data to be provided. For these preparations with a potential to contain toxic, addictive, psychotropic or other substances that may be of concern (given in the Compendium), presumption of safety can be applied only if there is convincing evidence that these undesirable substances in the specific plant parts or preparations are either absent in the source material, or significantly reduced if not excluded, or inactivated during processing (EFSA Journal, 2009).

\section{Discussion on regulatory challenges}

Herbs and their preparations obtained from plants, algae, fungi or lichens are widespread in the EU in the form of food supplements. They can be purchased at pharmacies, supermarkets, and specialty stores or online. Although most of these products have a long history of use in Europe, there are some concerns in terms of safety and quality. Contamination (chemical and microbiological) is a problem, associated for example with herbal products from Asia. Food supplements use is associated with 23000 emergency department visit and 2000 hospitalizations in the United States each year (Geller et al., 2015). Adulteration with synthetic drugs is prevalent in, although not limited to food supplements intended to weight-loss, sport performance and erectyle and libido disfunction. Cases of death in Europe and the United States consuming products contaminated with heavy metals, synthetic drugs and other undesirable substances are reported.

Although absolute safety does not exist, information about traditional use is an important element in the assessment of the safety of traditionally used botanicals and their preparations. History of use should, as a minimum, cover use during one generation - 25 years. It has advantages for manufacturers and regulators. When botanicals are used in equivalent forms and under comparable conditions for use, as described in traditional information and after analyzing all existing data, it ensures that the botanicals and their preparations used in the food supplements will not endanger the health of consumers. In the absence of reports or other safety-relevant information, it may be used to avoid the need for further toxicological tests (Anton et al., 2012). But this can obviously not exclude the

\footnotetext{
*marjan.dzeparoski@bionikapharm.com
} 
emergence of new security issues that have not yet been identified. An important aspect of the food law is the so-called obligation to notify, arising from Article 19. This routine surveillance request, combined with the RASFF, links all the European security authorities of the Member States and constitutes a powerful tool for identifying unexpected untoward effects of specific herbal food supplements in the early stage and taking appropriate actions like recalls (Coppens et al., 2006). RASFF Consumer Portal, the consumer friendly internet tool was launched in June 2004. Through RASSF has been registered occurence of yohimbine, vinpocetine, evodiamine, huperzine A, vincamine, vinburnine, arecoline, higenamine, Evodia ruteacarpa, Huperzia serrata and other unauthorized substances in the food supplements. Post-marketing surveillance is therefore an essential tool, organized by some member states in a systematic way.

In France, for example, ANSES implemented the "Nutrivigilance" system in 2010 and health professionals can report an adverse health reaction directly online or private individuals/patients can do this through their doctor or pharmacist, or directly through the French Ministry of Health's adverse event reporting portal. In the framework of the Act of 13 October 2014 on the future of agriculture, food and forests, ANSES has been entrusted with setting up a phytopharmacovigilance scheme.

In recent years there has been an increase in reported adverse events from the use of food supplements. This is also because of the mandatory reporting to FDA of serious adverse events (events that require medical intervention to prevent death, hospitalization or birth defect) for dietary supplements from 22 December 2007 by manufacturers, packers and distributors.

\section{Conclusion}

Since the early history of humans and up until now botanicals have been widely used. Popularity of food supplements is increasing all over the world, which is helped with the perception that herbal food supplements are natural and therefore safe. The market of herbal food supplements is expected to grow even further in the future as disease prevention, healthier living, modern habits, longer quality lifespan are a top concern of many people. Contamination (chemical and microbiological) is a problem, associated for example with herbal products from Asia. Cases of death in Europe and the United States consuming products contaminated with heavy metals, synthetic drugs and other undesirable substances are reported. Food supplements can and provoke adverse events. They can have pharmacological effects and therefore can have serious adverse events. Traditional use is a key source of information to demonstrate the safety of many botanicals and their preparations. Safety of food supplements that for is of utmost importance. Despite RASFF in Europe, post-marketing surveillance is an essential tool organized by some states in a systematic manner to protect consumers. In other countries suspected adverse events from food supplements can only be reported as part of the concomitant therapy with reports for the medicinal products or medical devices, where probable cause and effect relationship can be established. In France ANSES implemented the Nutrivigilance system in 2010. In USA, in recent years there has been an increase in reported adverse events from the use of food supplements. This should be followed also by other states together with regulation harmonization, which will mitigate their risks and make the use of herbal/food supplements with nutrivigilance much safer.

\section{References}

Anton, R., Serafini, M., Delmulle, L., 2012. Traditional knowledge for the assessment of health effects for botanicals - A framework for data collection. EFFL 2, 74-80.

Coppens, P., Delmulle, L., Gulati, O., Richardson, D., Ruthsatz, M., Sievers, H., Sidani, S., 2006. Use of botanicals in food supplements. Ann. Nutr. Metab. 50, 538-554.

Geller, A.I., Shehab, N., Weidle, N.J., Lovegrove, M.C., Wolpert, B.J., Timbo, B.B., Mozersky, R.P., Budnidz, D.S., 2015. Emergency department visits for adverse events related to dietary supplements. N. Engl. J. Med. 373(16), 1531-1540.

Guidance on Safety assessment on botanicals and botanical preparations intended for use as ingredients in food supplements, 2009. EFSA Journal 7(9), 1249, pp. 25 .

Maced. Pharm. Bull. 66 (Suppl 1) 189 - 190 (2020) 